DOI: $10.31249 / \mathrm{rsm} / 2018.02 .15$

\title{
Г.T. Сардарян
}

\section{ПОАИТИЧЕСКАЯ АОКТРИНА ПАПЫ БЕНЕАИКТА ХVI И ЕВРОПЕЙСКИЙ ПОАИТИЧЕСКИЙ ПОЗИТИВИЗМ}

Аннотация. В данной статье речь идет о католической политической доктрине, сформулированной в период понтификата Бенедикта XVI. Изучаются описанные в энцикликах понтифика основы государственной власти, соотночение норм морали и права, нравственности и политики. Автор приходит к выводу, что способы решения проблем, которые предлагал Бенедикт XVI в период своего понтификата, до сих пор не потеряли свою актуальность.

Ключевые слова: Католическая политическая доктрина, Ватикан, Бенедикт XVI, Папа Римский, демократия, либерализм, коммунизм, позитивизм, энциклика, политическая идеология.

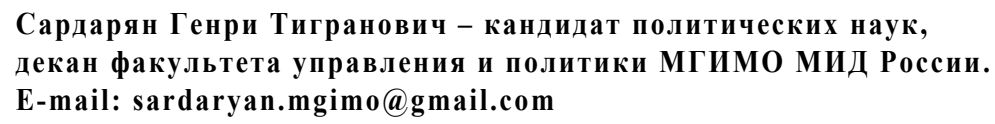

G.T. Sardarian. The Political Doctrine of Pope Benedict XVI and the European Political Positivism

Abstract. This article addresses the Catholic political doctrine formulated during the period of the pontificate of Benedict XVI. The fundamentals of state power described in the encyclicals of the pontiff, the correlation of morality and law, morality and politics are described in the article. The author comes to a conclusion that the ways of solving the problems that Benedict XVI offered during his pontificate have not lost their relevance.

Keywords: Catholic political doctrine, Vatican, Benedict XVI, Pope, democracy, liberalism, communism, positivism, encyclical, political ideology.

Sardaryan Genri Tigranovich - Candidate of Political Sciences,

Dean of the School of Governance and Politics

of the Moscow State Institute of International Relations.

E-mail: sardaryan.mgimo@gmail.com 
Йозеф Алоиз Ратцингер, будущий Папа Римский Бенедикт XVI, в 1932 г., будучи школьником, переехал со своей семьей в немецкий город Ашау-имКимгау. Через год к власти пришли нацисты. Он вспоминал, что роль церкви в этом городе изначально была центральной, и новые власти, чтобы не вызвать острой реакции местных жителей, не решились начать с резких нападок в ее адрес. Большинство школьных учителей Ратцингера даже если и не были убежденными христианами, тем не менее на бытовом уровне со скепсисом относились к новому режиму. Однако один из них, став ярым сторонником нацистов, решил нарушить традиционную картину и установил в самом центре города «майское дерево» - украшенный высокий столб, который должен был символизировать собой германскую культуру и оттеснить христианские традиции. Затем он стал организовывать праздники летнего солнцестояния, утверждая, что истинная германская культура не имела понятий греха и искупления, что это было навязано еврейскими традициями посредством христианства.

Проводя параллели с современностью, Йозеф Ратцингер удивлялся, насколько такая позиция похожа на современные утверждения о том, что христианство уничтожает индивидуальную культурную идентичность и не мешает распространению общеевропейских ценностей $[10$, p. 8].

В 1977 г., после долгой карьеры в качестве профессора теологии в нескольких немецких университетах, Ратцингер был назначен Папой Павлом VI архиепископом Мюнхена и Фрайзинга, а также и кардиналом. В 1981 г. он стал префектом Конгрегации доктрины веры - старейшей и главной из девяти Конгрегаций Римской курии, которая осуществляет наблюдение за чистотой вероучения и морали в Римско-католической церкви.

Ратцингер был избран Папой Римским на второй день конклава, 19 апреля 2005 г., взяв себе имя Бенедикт XVI, в честь своего предшественника, Бенедикта XV, который был Папой в период Первой мировой войны. Вполне возможно, что новый Папа подчеркивал своим именем и преемственность с деятельностью Бенедикта Нурсийского - основателя первого в Европе монастырского ордена со строгим уставом, покровителя Европы. Бенедикт XVI оставался понтификом на протяжении восьми лет. За эти годы им были опубликованы три энциклики, две из которых касаются в том числе вопросов, составляющих политическую доктрину католицизма.

Первый вопрос политического характера, которого касается Бенедикт XVI в своей первой энциклике «Deus caritas est» от 2005 г. - секулярность. Он рассматривает ее сквозь призму общественной справедливости, ссылаясь на слова Августина Блаженного о государстве как о банде разбойников, если в нем нет справедливости [11, p. 115]. Определив справедливость как начальную точку и окончательный смысл политики, понтифик тем не менее не допускает возможности для Церкви вступать в политическую борьбу 
ради построения справедливого общества. По его мнению, это будет значить, что Церковь стремится подменить собой государство. Но и статус стороннего наблюдателя в этой борьбе для него неприемлем. Он отводит Церкви роль морально-нравственного ориентира, который должен сформировать духовную основу для достижения справедливости [8].

Тема справедливости продолжается в рамках рассмотрения традиционного вопроса противостояния марксизма и капитализма в энциклике «Spe Salvi» от 2007 г. Корни проблемы понтифик видит в так называемой «вере в прогресс», которую сформулировал еще Фрэнсис Бэкон в XVI в. Через несколько веков, по мнению Бенедикта XVI, все большее ускорение технического развития и связанная с ним индустриализация породили совершенно новую социальную ситуацию: сформировался класс индустриальных рабочих и так называемый «промышленный пролетариат», ужасные условия жизни которого красноречиво описал Фридрих Энгельс в 1845 г. [9].

O последовавших революционных событиях Бенедикт XVI говорит как о некоем неизбежном результате этих обстоятельств - после революции во Франции 1789 г. настал час для новой революции, пролетарской. Прогресс не мог продвигаться линейно, маленькими шагами, ему требовался революционный скачок.

Бенедикт XVI очень высоко оценивает аналитические способности Маркса, в особенности в части описания сложившейся в мире ситуации и необходимых шагов для осуществления революции. При этом Папа обращает внимание на фундаментальную ошибку марксизма - отсутствие картины будущего. В результате «после революции Ленину пришлось столкнуться с тем, что в трудах его учителя нет никаких указаний о том, как действовать дальше. Да, он говорил о промежуточной фазе диктатуры пролетариата как об одной из необходимостей, которая, однако, в дальнейшем исчезнет сама собой. Мы прекрасно знаем эту “промежуточную фазу” и знаем, как она развивалась дальше, оставляя за собой удручающее разрушение, вместо того чтобы оздоровлять мир. Маркс не просто не продумал необходимых для нового мира элементов и институтов - тот в них уже не должен был нуждаться. Сам факт, что он ничего не говорит об этом, является логическим следствием его позиции» [4].

Анализируя Маркса, Бенедикт XVI в традиционном для Ватикана ключе выделяет материализм как главную ошибку данной идеологии. Человек, по мнению Папы, представляет собой не только плод экономических условий, улучшение его жизни не равно улучшению материальных условий.

В этом же ключе Папа рассматривает идею прогресса как таковую. Критикуя приведенную выше «веру в прогресс», Бенедикт XVI приводит слова Теодора Адорно - немецкого философа, представителя Франкфуртской 
критической школы, который утверждал, что при ближайшем рассмотрении прогресс - это движение от пращи к мегабомбе [2, p. 312].

Церковь, до этого системно критиковавшая наиболее крупные универсалистские идеалистические политические учения, либерализм и коммунизм, формулирует общую позицию по отношению к идеализму как таковому: благополучие мира нельзя обеспечить лишь структурами, сколь бы действенными они ни были. По мнению понтифика, даже лучшие структуры функционируют лишь при условии, что в обществе живы убеждения, способные мотивировать людей к добровольному соблюдению общественного порядка.

В действительности современный мир является наглядным свидетельством данного утверждения. Там, где конституции и законодательство не опираются на систему ценностей и цивилизационное наследие, соотносящееся с закрепленными правовыми нормами, там, где многочисленные механизмы управления государством и разделения властей не находят опоры в социуме они носят формальный характер и в действительности не функционируют.

Конституция Сомали практически полностью цитирует текст Всеобщей декларации прав человека, при этом в ней оговаривается, что ислам является государственной религией, ни одна другая религия проповедоваться не может, а любой закон должен соответствовать нормам шариата. В результате 13-летняя Аиша Ибрагим Духуло была приговорена к смертной казни путем закидывания камнями за то, что ее же изнасиловали трое мужчин, что в соответствии с нормами шариата является ее виной [4].

В этом же ключе Бенедикт XVI продолжает разговор и в энциклике «Caritas in Veritate». Он утверждает: исторически люди полагали, что достаточно организовать надлежащие учреждения, чтобы гарантировать человечеству право на развитие. Однако этого в действительности недостаточно, так как целостное человеческое развитие подразумевает свободное и солидарное принятие на себя ответственности всеми членами общества [7]. При этом многие процессы, которые до этого вызывали положительную реакцию Ватикана и всего международного сообщества, такие как международная интеграция и глобализация, стали проявлять свои очевидные отрицательные стороны. В частности, Бенедикт XVI обращает внимание на то, что в прошлом основной акцент в вопросах развития делался на государственную власть, существующую в национальных границах. Понтифик же становится свидетелем другого мира, в котором суверенитет государства оказывается существенно ограничен наднациональным контекстом. Это, в свою очередь, требует пересмотра и функций, и полномочий государства.

Глобализация рынка, по мнению Бенедикта XVI, приводит к тому, что развитые страны стараются локализовать производство в тех местах, где издержки производства ниже. Это стимулирует новые формы конкуренции между государствами, желающими привлечь на свою территорию производ- 
ственные мощности иностранных корпораций, а, следовательно, уровень социальной защиты снижается. Международные финансовые институты оказывают давление на бюджетную политику различных стран, заставляя их сокращать социальные расходы на фоне отсутствия реальной защиты трудящихся со стороны профсоюзных ассоциаций. Ряд современных ученых сходятся во мнении, что изначальный оптимизм относительно перспектив финансовой глобализации по предоставлению всеобщего доступа к дешевым кредитам теперь вызывает множество вопросов, в особенности после кризиса 2008 г. и предпринятых в связи с этим мер по стабилизации системы [13, p. 2].

Бенедикт XVI говорит о распределительной справедливости, которая должна играть важную роль не только для политической, но и для экономической системы. Такого рода справедливость приводит больше к внутренней солидарности и взаимному доверию, без которых исполнение рынком своих функций становится проблематичным. Понтифик не видит возможности для экономики решить все социальные проблемы только с помощью коммерческой логики. Забота о достижении общего блага должна быть возложена в первую очередь на политическое сообщество.

Отрыв экономической деятельности, которая стремится лишь производить богатство, от политической, которая должна обеспечивать справедливость путем перераспределения, приводит к тяжелым последствиям. При этом последовательность, которая считалась нормальной в прошлом и при которой сначала создавалось богатство, затем оно перераспределялось политической властью, в условиях глобализации кажется понтифику неэффективной. Сегодня производство выходит далеко за пределы государственных границ, а политическая власть продолжает оставаться локальной. Таким образом, речь идет о дихотомии в восприятии глобализации: с одной стороны, это благо, потому что может помочь решить проблемы с бедностью, неравенством, доступом к технологиям и пр. С другой же стороны, глобализация создает еще большее неравенство, бедность и отсталость развивающихся стран. Бенедикт XVI обращает, например, внимание на то, что делокализация производства ослабляет в предпринимателе ответственность перед работниками, поставщиками, потребителями, а также перед природной средой и местным обществом. Поэтому Ватикан призывает осуждать не сам инструмент - глобализацию, а человека, который пользуется этим инструментом неправильно.

В конце 2000-х годов становятся популярными теории о неумолимом конце самого государства в условиях глобализации. Международные финансовые потоки, крупнейшие корпорации, медиаимперии, Интернет и ряд других явлений, по мнению ряда ученых, вскоре сделают существование государства и государственной власти бессмысленными [5, p. 124]. Понтифик же 
призывал не спешить с похоронами государства, так как для преодоления финансово-экономического кризиса той эпохи роль государства представлялась ему ключевой; в действительности именно точка зрения Бенедикта XVI оказалась справедливой. При этом однозначно положительным явлением Святой престол считает дробление политической власти на местном, национальном и международном уровнях, что должно позволить управлять экономической глобализацией, не подрывая при этом основ демократии. Подобное представление гармонично вытекает из традиционного католического принципа субсидиарности, т.е. вспомогательной роли центральной власти в решении социальных проблем.

Понтифик приводит примеры успешной реализации принципов солидарности и субсидиарности посредством исключительно рыночных механизмов: система этической сертификации социальной ответственности бизнеса, этические счета и инвестиционные фонды, микрокредитование и микрофинансирование. Причем оба этих принципа должны реализовываться совместно, так как Бенедикт XVI убежден, что если субсидиарность без солидарности вырождается в социальный партикуляризм, то солидарность без субсидиарности превращается в патерналистскую опеку, которая унижает нуждающегося.

В период понтификата Бенедикта XVI становится все более очевидной проблема интеграции большого числа мигрантов в европейское общество. К моменту издания энциклики практически во всех странах - членах Европейского союза количество мигрантов из неевропейских государств превышало их число из стран ЕС [3, p. 65]. Во Франции, по данным Французского национального института статистики (INSEE), в 2008 г. проживали 5,3 млн иммигрантов иностранного происхождения и 6,5 млн прямых потомков иммигрантов (родившихся во Франции с хотя бы одним родителем-иммигрантом), что в совокупности составляет 11,8 млн человек и $19 \%$ от общей численности населения Франции. Из них около 4 млн человек - арабоберберского происхождения, 1 млн человек - африканского и 400 тыс. человек - турецкого происхождения [6]. Если в случае с 5 млн европейцев, переместившихся из различных стран, существенных проблем с интеграцией в общество страны пребывания не возникает, то, по данным исследовательского центра «Montaigne Institute», около 30\% французских мусульман выступают за отмену светского законодательства и введение вместо него шариата, 80\% - требуют введения халяльного питания в школах [12].

В своей энциклике Бенедикт XVI описывает две ошибки европейских политиков в вопросе интеграции мигрантов: культурный эклектизм и сглаживание культурных различий. В первом случае речь идет о том, что различные культуры рассматриваются как равноценные и взаимозаменяемые, что Бенедикт XVI воспринимает как уступку релятивизму. В результате же поли- 
тики сглаживания различий утрачивается культура разных наций, традиции разных народов, в рамках которых человек ищет ответ на фундаментальные вопросы существования. То есть, с одной стороны, христианской культуре и цивилизационному наследию приписывается такой же статус, как и исламу или любой другой религиозной группе, несмотря на то что вся система политического, экономического, культурного и социального устройства Европы сформировалась в первую очередь под влиянием именно христианского наследия. С другой стороны, глобализация стирает культуру как таковую, не оставляя того же самого наследия.

Для того чтобы сделать глобализацию управляемой, развивать мировую экономику, оздоровить экономические системы, достичь целостного разоружения, продовольственной безопасности, упорядочить миграционные потоки, Бенедикт XVI полагает необходимым создать настоящую всемирную политическую власть, которая должна руководствоваться правом, придерживаться принципов субсидиарности и солидарности, стремиться к общему благу, иначе стабильность международных институтов будет опираться исключительно на баланс сил между великими державами. Создавать такую власть следовало с помощью уже существующих институтов, в первую очередь ООН. Параллельно речь шла и о пересмотре традиционной модели международного взаимодействия: понтифик отмечает, что необходимо учреждение более высокой ступени международной власти субсидиарного типа для управления глобализацией.

В 2011 г. Бенедикт XVI посетил Бундестаг Германии и посвятил свое выступление вопросу дихотомии права и морали. По его мнению, исторические системы права почти всегда основывались на религии: решения о законности принимались со ссылкой на божественность. В отличие от других мировых религий, христианство никогда не предлагало государству и обществу юридического порядка, вытекающего из Евангелия. Христианство указывало на природу и разум как на истинные источники права. Христианские богословы таким образом присоединились к философскому и юридическому движению, которое начало складываться во II в. до н. э. Христианский брак между законом и философией открыл путь, который привел через христианское Средневековье к Декларации прав человека и Основного закона Германии 1949 г., в котором содержится обязательство государства охранять неотьемлемые права человека [1].

В своем послании Бенедикт XVI выступает с критикой позитивизма, взяв за объект критики позицию Ганса Келзена - австрийского юриста и философа, теоретика права, основателя и судьи Конституционного суда Австрии. По словам Келзена, природа - совокупность объективных данных, связанных вместе причиной и следствием, что не допускает существования каких бы то ни было этических основ. 
Бенедикт XVI подчеркивает, что функциональный характер позитивистской концепции природы неспособен создать мост к этике и закону. По его мнению, этика и религия должны быть отнесены к субъективной области, они остаются посторонними для разума. Понтифик особенно подчеркивает данную проблему в связи с развитием Европы. Признать позитивизм как единственную основу для законотворчества - значит уменьшить все другие идеи и ценности до уровня субкультуры. В результате этого европейская культура как мировой феномен может исчезнуть - на фоне появления экстремистских и радикальных движений, готовых к заполнению вакуума.

Через два года после данного выступления Бенедикт XVI на консистории (собрании кардиналов, созываемом и возглавляемом Папой Римским) объявил о своем решении отречься от престола, став первым - после Григория XII - отказавшимся от своего титула понтификом за 600 лет.

Между тем кризис идентичности в Европе лишь нарастает. Чередой идут события, которые невозможно было предугадать десятилетие назад: выход Великобритании из ЕС, появление новых политических сил, выступающих категорически против сложившейся модели глобализации и политикоэкономической интеграции. Стал популярным тезис о консервативном развороте на Западе. Однако в отличие от либерализма и социализма, консерватизм, как правило, локален. Он не ставит целью стирание границ и различий, он, скорее, ратует за сохранение традиций. По этой причине после выборов в парламент ЕС у евроскептиков зачастую возникают проблемы с формированием единой фракции, а поиск единой платформы для сотрудничества редко приводит к успеху.

Между тем запрос населения европейских стран на консерватизм очевиден и проявляется все ярче с каждыми новыми выборами. Полномасштабный ответ политических элит на этот запрос в настоящее время отсутствует. Большинство так называемых «новых» политических партий пытаются исходить из той парадигмы, с которой призваны бороться - якобинским представлением о недопустимости любой роли религии в обществе и государстве. Параллельно на территории европейских стран формируется исламская община, вопреки всем предсказаниям либеральных аналитиков с каждым поколением все более клерикализирующаяся, обладающая высокой степенью политической активности и демографическим преимуществом перед представителями местного населения. Каковы будут последствия подобной ситуации - вполне предсказуемо.

В этой связи представляется, что христианское наследие - единственная общая платформа для сотрудничества и совместного развития консервативного политического блока на Западе. 


\section{Библиография}

1. Address of His Holiness Benedict XVI to Reichstag. 2011. Sept. 22. URL: https://w2. vatican.va/content/benedict-xvi/en/speeches/2011/september/documents/hf_ben-xvi_spe_20110922_ reichstag-berlin.html (Дата обращения: 12.11.2017.)

2. Adorno T. Negative Dialectics. L.: Routledge, 2003. 448 p.

3. Balch A. Managing Labour Migration in Europe: Ideas, Knowledge and Policy Change. Oxford: Oxford University Press, 2010. 230 p.

4. Fisk R. The crimewave that shames the world // The Independent. 2010. Sept. 7. URL: http://www.independent.co.uk/voices/commentators/fisk/robert-fisk-the-crimewave-that-shames-theworld-2072201.html (Дата обращения: 14.10.2017.)

5. Held D., McGrew A. The Global Transformations Reader: An Introduction to the Globalization Debate 2 nd Edition. Cambrige: Polity Press, 2003. 624 p.

6. Insee Première. 2008. № 1287 // Institut national de la statistique et des études économiques. URL: https://www.insee.fr/fr/statistiques/fichier/1373650/T11F039.pdf\&ved=2ahUKEwiL7Y-684r ZAhWGlCwKHVVlCccQFjAEegQICRAB\&usg=AOvVaw0B9IEk-2tvwDi2mrOnKi3e (Дата обращения: 15.09.2017.)

7. Lettera Enciclica «Caritas in veritate» Del Sommo Pontefice Benedetto XVI // La Santa Sede. 2009. URL: http://w2.vatican.va/content/benedict-xvi/it/encyclicals/documents/hf_ben-xvi_ enc_20090629_caritas-in-veritate.html (Дата обращения: 15.09.2017.)

8. Lettera Enciclica «Deus caritas est» Del Sommo Pontefice Benedetto XVI // La Santa Sede. 2005. URL: http://w2.vatican.va/content/benedict-xvi/it/encyclicals/documents/hf_ben-xvi_enc_ 20051225 deus-caritas-est.html (Дата обращения: 15.09.2017.)

9. Lettera Enciclica «Spe Salvi» Del Sommo Pontefice Benedetto XVI [Электронный pecypc] // La Santa Sede. 2007. URL: http://w2.vatican.va/content/benedict-xvi/en/encyclicals/documents/hf_ ben-xvi_enc_20071130_spe-salvi.html (Дата обращения: 15.07.2017.)

10. Ratzinger J. Milestones: Memoirs, 1927-1977. San Francisco: Ignatius Press, 1998. 156 p.

11. Sant'Agostino. La Città di Dio. Vatican: Le vie della Cristianità, 2016. 1627 p.

12. Taylor A. What French Muslims think about France's secular laws // The Washington Post. 2016. Sept. 19. URL: https://www.washingtonpost.com/news/worldviews/wp/2016/09/19/whatfrench-muslims-think-about-frances-secular-laws/?utm_term=.ec4267eaa008 (Дата обращения: 26.07.2017.)

13. Welfens P.J.J. Social Security and Economic Globalization. Berlin: Springer Science \& Business Media, 2013. 147 p.

\section{References}

Address of His Holiness Benedict XVI to Reichstag. 2011. Sept. 22. URL: https://w2. vatican.va/content/benedict-xvi/en/speeches/2011/september/documents/hf_ben-xvi_spe_20110922_ reichstag-berlin.html (Data obrashhenija: 12.11.2017.)

Adorno T. Negative Dialectics. L.: Routledge, 2003. 448 p.

Balch A. Managing Labour Migration in Europe: Ideas, Knowledge and Policy Change. Oxford: Oxford University Press, 2010. 230 p.

Fisk R. The crimewave that shames the world // The Independent. 2010. Sept. 7. URL: http://www.independent.co.uk/voices/commentators/fisk/robert-fisk-the-crimewave-that-shames-theworld-2072201.html (Data obrashhenija: 14.10.2017.)

Held D., McGrew A. The Global Transformations Reader: An Introduction to the Globalization Debate 2 nd Edition. Cambrige: Polity Press, 2003. 624 p. 


\section{РАЗМЫШЛЕНИЯ, СООБЩЕНИЯ, КОММЕНТАРИИ}

Insee Première. 2008. N 1287 // Institut national de la statistique et des études économiques. URL: $\quad$ https://www.insee.fr/fr/statistiques/fichier/1373650/T11F039.pdf\&ved=2ahUKEwiL7Y684rZAhWGlCwKHVVlCccQFjAEegQICRAB\&usg=AOvVaw0B9IEk-2tvwDi2mrOnKi3e (Data obrashhenija: 15.09.2017.)

Lettera Enciclica «Caritas in veritate» Del Sommo Pontefice Benedetto XVI // La Santa Sede. 2009. URL: http://w2.vatican.va/content/benedict-xvi/it/encyclicals/documents/hf_ben-xvi_enc_ 20090629_caritas-in-veritate.html (Data obrashhenija: 15.09.2017.)

Lettera Enciclica «Deus caritas est» Del Sommo Pontefice Benedetto XVI // La Santa Sede. 2005. URL: http://w2.vatican.va/content/benedict-xvi/it/encyclicals/documents/hf_ben-xvi_enc_ 20051225_deus-caritas-est.html (Data obrashhenija: 15.09.2017.)

Lettera Enciclica «Spe Salvi» Del Sommo Pontefice Benedetto XVI [Электронный ресурс] // La Santa Sede. 2007. URL: http://w2.vatican.va/content/benedict-xvi/en/encyclicals/documents/ hf_ben-xvi_enc_20071130_spe-salvi.html (Data obrashhenija: 15.07.2017.)

Ratzinger J. Milestones: Memoirs, 1927-1977. San Francisco: Ignatius Press, 1998. 156 p.

Sant'Agostino. La Città di Dio. Vatican: Le vie della Cristianità, 2016. 1627 p.

Taylor A. What French Muslims think about France's secular laws // The Washington Post. 2016. Sept. 19. URL: https://www.washingtonpost.com/news/worldviews/wp/2016/09/19/whatfrench-muslims-think-about-frances-secular-laws/?utm_term=.ec4267eaa008 (Data obrashhenija: 26.07.2017.)

Welfens P.J.J. Social Security and Economic Globalization. Berlin: Springer Science \& Business Media, 2013. 147 p. 